\section{BMJ Paediatrics Open}

\title{
Antacid therapy for gastroesophageal reflux in preterm infants: a systematic review
}

Elda Dermyshi, Charley Mackie, Phoebe Kigozi, Bernard Schoonakker, Jon Dorling

To cite: Dermyshi E, Mackie C, Kigozi P, et al. Antacid therapy for gastroesophageal reflux in preterm infants: a systematic review. BMJ Paediatrics Open 2018;2:e000287. doi:10.1136/ bmjpo-2018-000287

Received 12 March 2018 Revised 12 May 2018 Accepted 14 May 2018

\section{Check for updates}

(c) Author(s) (or their employer(s)) 2018. Re-use permitted under CC BY-NC. No commercial re-use. See rights and permissions. Published by BMJ.

Neonatal Intensive Care Unit, Nottingham University Hospitals, Nottingham, UK

Correspondence to Dr Elda Dermyshi; elda. dermyshi@yahoo.com

\section{ABSTRACT}

Background Gastro-oesophageal reflux is prevalent in preterm infants. Despite widespread use in clinical practice, there is still much controversy over the efficacy and safety of drug interventions, particularly antacid therapy.

Objective To systematically review the effects of antacid therapy on preterm infants with symptoms of gastrooesophageal reflux, and to assess the safety of these interventions.

Methods We carried out an electronic search of the Cochrane central register of controlled trials (CENTRAL, The Cochrane Library), MEDLINE (1966-present), EMBASE (1980-present) and CINAHL (1982-present) as well as other online sources. Participants were preterm infants ( $<37$ weeks gestation) with gastro-oesophageal reflux disease who were receiving care on a neonatal unit. We assessed the effects of histamine-2 receptor antagonists, proton pump inhibitors and alginates against placebo, primarily to see if they reduced the symptoms of reflux. Results Six studies were included in this review. Metaanalysis could not be carried out due to a lack of studies assessing the same intervention with the same outcomes. Omeprazole therapy significantly reduced the oesophageal acid exposure percentage time with $\mathrm{pH}<4(\mathrm{p}<0.01)$ and sodium alginate significantly decreased gastrooesophageal reflux episodes $(p=0.024)$. Metoclopramide and ranitidine showed a significant increase in gastrooesophageal reflux disease symptoms versus placebo $(p<0.04)$. No significant results were found for the use of esomeprazole or lansoprazole versus placebo.

Conclusions There is insufficient evidence available to conclude whether antacid therapy is effective or safe when treating gastro-oesophageal reflux disease in preterm infants. Further research is needed into this topic and caution should be taken when administering antacids to preterm infants.

\section{Trial registration number CRD42017078778}

\section{BACKGROUND}

Gastro-oesophageal reflux (GOR) is a prominent condition among preterm infants. Symptoms such as apnoeas, desaturation, bradycardia, vomiting, poor weight gain and irritability have been attributable to GOR, which is called gastro-oesophageal reflux disease (GORD), when symptoms are severe. GORD has been reported to cause irritability,
What is already known on this topic?

Gastro-oesophageal reflux is a prominent condition among preterm infants.

- Antacids are often used to treat gastro-oesophageal reflux disease (GORD), despite the lack of good quality evidence to support its use.

- Studies have shown a significant positive correlation between the use of histamine-2 receptor antagonists and important complications.

\section{What this study hopes to add?}

There is limited evidence supporting the use of antacids in preterm infants.

- Omeprazole reduced gastric and oesophageal pH but did not alter GORD symptoms. Esomeprazole and lansoprazole had no significant effect on GORD signs and symptoms.

- Combined use of ranitidine and metoclopramide appears countereffective, with placebo periods giving less bradycardia episodes versus drug periods.

frequent vomiting, apnoea and bradycardia, aspiration pneumonia, aversion to feeding and exacerbation of chronic lung disease in term and preterm infants with associated resource implications from longer hospital stays.

Despite this, controversy remains over how it should be treated. Currently, non-pharmacological therapies are generally the first line of treatment in GORD with pharmacological therapies reserved for those who do not respond. ${ }^{1}$ Antacids containing alginate, histamine-2 receptor antagonists (H2 RAs) and proton pump inhibitors (PPI) are among the most common interventions used with $60 \%$, $53 \%$ and $23 \%$ of UK neonatal units using these products, respectively. ${ }^{2}$

Studies have also shown a significant correlation between the use of H2 RAs and important complications. ${ }^{3}{ }^{4}$ Guillet et al showed H2-blocker use was associated with an increased incidence of necrotising 
enterocolitis (NEC) (OR 1.71; 95\% CI 1.34 to 2.19; $\mathrm{p}<0.0001){ }^{3}$

There continues to be a widespread use of antacid therapy in neonatal units today despite the evidence gaps. This review was carried out to systematically evaluate the evidence of efficacy and safety of antacid treatment for GORD in preterm infants and to highlight potential areas for future research.

\section{OBJECTIVES}

\section{Primary objective}

To assess the efficacy of antacid therapy in preterm infants diagnosed with GORD.

\section{Secondary objective}

To assess the safety of antacid therapy in preterm infants diagnosed with GORD.

\section{MATERIALS AND METHODS}

We used Preferred Reporting Items for Systematic Reviews and Meta-analyses guidelines and the Cochrane Handbook of Systematic Reviews of Interventions approach for conducting and reporting systematic reviews and meta-analyses of randomised controlled trials (RCTs).$^{56}$ The methodology of this systematic review was published in PROSPERO (www.crd.york.ac.uk/PROSPERO; ref CRD42017078778).

\section{Search methods for identification of studies}

MEDLINE/PubMed, Embase, Wiley Online Library, Cochrane Library and Web of Science databases were searched to identify trials of antacid therapy in preterm infants. Databases were screened for publications from the earliest available date until 15 October 2017. No language restrictions were applied. Ethical approval was not required because only published articles were included in this review. A database search of clinicaltrials. gov for ongoing and completed trials was also carried out, using the search terms infant or preterm and reflux or gastroesophageal reflux. Trials reported as abstracts or letters to the editor were included if sufficient data to fulfil the inclusion criteria were presented within the report, or provided by authors. Full search strategy is presented in online supplementary appendix 1 .

\section{Eligibility criteria}

All relevant randomised trials involving preterm infants $(<37$ weeks gestation) with GORD (clinical diagnosis and/or 24 hours intraoesophageal $\mathrm{pH}$ monitoring, or impedance studies) receiving care on a neonatal unit. Crossover, randomised trials or quasi-randomised studies, described in some way as to suggest or imply that the study was randomised if the demographic detail of each group was similar were included.

\section{Types of interventions}

We included all available RCTs evaluating antacid therapies for GOR in preterm neonates. Antacid therapy (administered by any method) should have been commenced after the diagnosis of GORD and continued for any duration.

The interventions considered were:

- H2 RAs versus a placebo or standard care/non-pharmacological therapy.

- PPIs versus a placebo or standard care/non-pharmacological therapy.

- Alginates versus a placebo or standard care/non-pharmacological therapy.

Trials were not limited by dose, frequency or duration of intervention.

\section{Selection of studies}

Paired reviewers (ED, CM, BS, JD) independently screened titles, abstracts and then full texts for eligibility, assessed risk of bias and collected data from included studies. Any disagreement between reviewers was resolved through discussion or adjudication by a third reviewer (BS, JD). In case of duplicate publications, the most recent and updated report of the study was included.

\section{Risk of bias and quality of evidence assessment}

The Cochrane Risk-of-Bias Tool was used to assess the risk of bias. ${ }^{7}$ The quality of the evidence of outcomes was rated by the Grading of Recommendations Assessment, Development, and Evaluation (GRADE) approach. ${ }^{8}$

\section{Data extraction}

From each eligible study the following information was collected: study characteristics (eg, author name, year of publication, sample size, patient characteristics, antacid type, duration of intervention, dosage and any of our preplanned clinical outcomes).

\section{Primary outcomes}

A reduction in reflux symptoms assessed by a reflux index score or bedside symptom charts. ${ }^{9}$ Clinical symptoms include the following: total GOR episodes, vomit/ regurgitations, choking/coughing, bradycardia attributed to GOR, behavioural/crying, feeding difficulties, irritability or pain, recurrent postprandial apnoeas and oxygen desaturation within 2 hours postprandial period.

\section{Secondary outcomes \\ - Time taken to establish full enteral feeds \\ - Length of hospital stay \\ - NEC (Bell's stage 2 or greater) \\ - Suspected or proven sepsis \\ - Other adverse effects}

\section{Statistical analysis}

We planned to analyse treatment effects in the individual trials using Review Manager 5.3 software, with risk ratio and risk difference for dichotomous data and mean difference for continuous data, with respective 
95\% CIs. However, given the small number of included studies, their varying methodologies and interventions, we judged quantitative meta-analysis to be inappropriate and instead report a narrative description of each study. Data are presented as reported in individual studies. We had also planned to conduct a number of subgroup analyses, which are detailed in the study protocol. The small number of studies, with small sample sizes and variable methods precluded subgroup analyses.

\section{RESULTS}

\section{Description of studies}

A total of 20139 records were identified by the initial search; 18909 were excluded as they were duplicates, or systematic reviews; 1230 titles and abstracts were screened and 1202 were excluded. Twenty-eight full-text articles were assessed for eligibility and six studies met our inclusion criteria (figure 1).

All included studies were double-blind, randomised, placebo-controlled trials. Four of the six were crossover trials (Wheatley and Kennedy, ${ }^{10}$ Omari et al, ${ }^{11}$ Corvaglia et $a l^{12}$ Corvaglia $e t a l^{13}$ ), while the remaining two were parallel trials (Orenstein $e t a l^{14}$ and Davidson $e t a l^{15}$ ).

The main characteristics of included RCTs are described in table 1 and excluded studies are summarised in online supplementary appendix 2.

Risks of bias assessments of trials are summarised in figure 2 and online supplementary appendix 3 . The evaluations of the level of evidence of outcomes according to the GRADE approach are summarised in online supplementary appendix 4 .

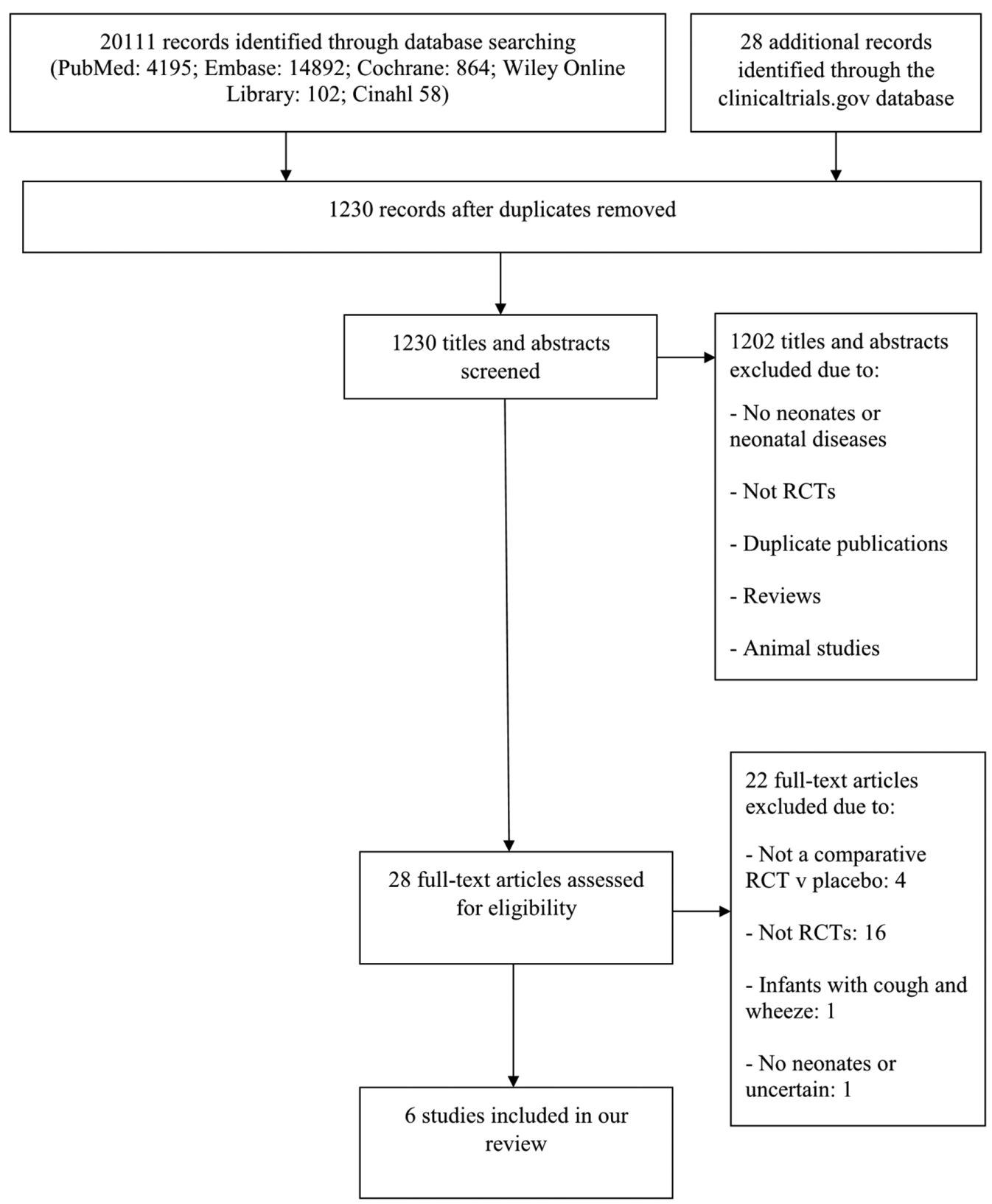

Figure 1 Study flow diagram. RCT, randomised controlled trial. 


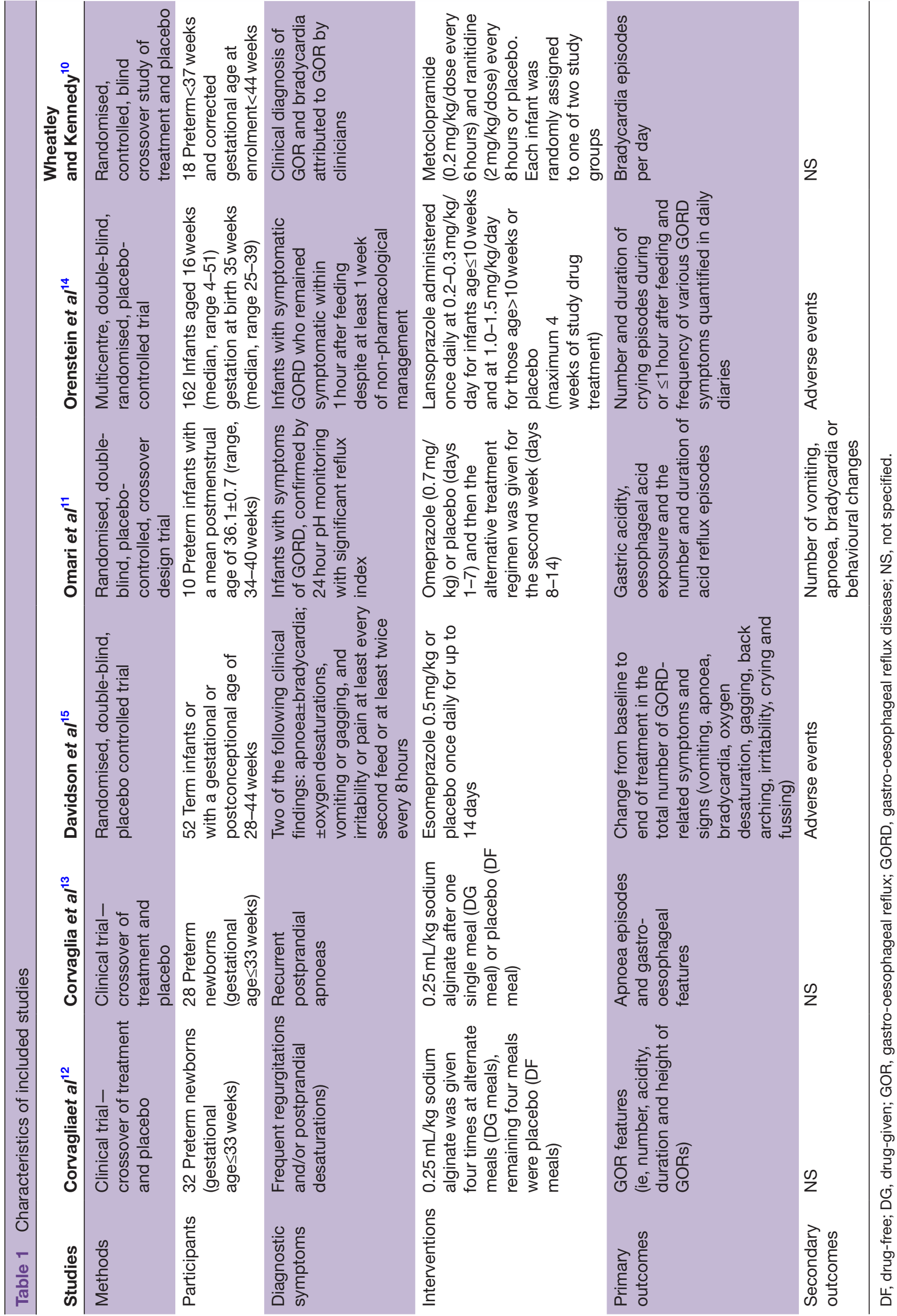




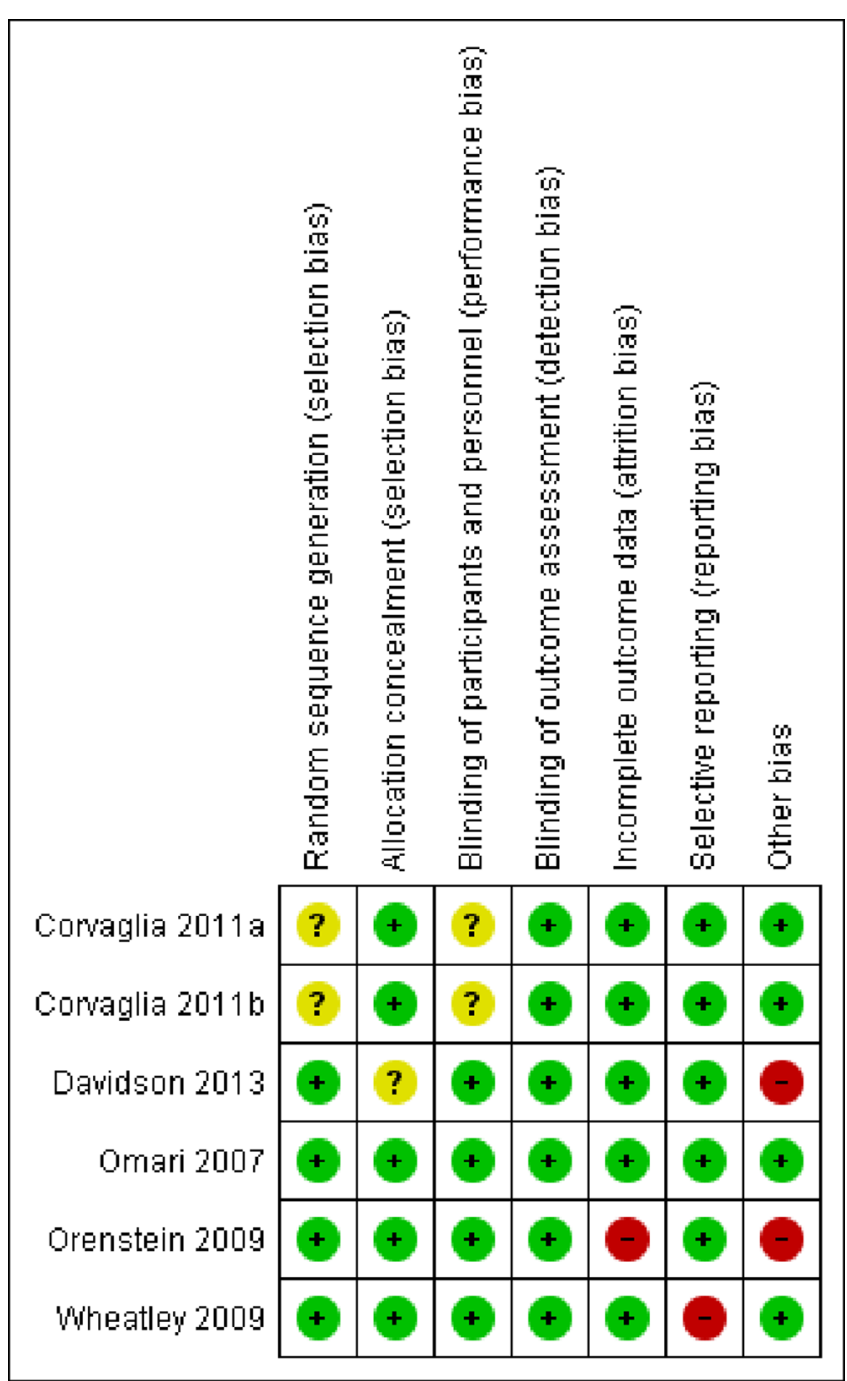

Figure 2 Risk of bias summary.

A total of 302 participants were enrolled in the six included trials, of which, four studies included only preterm infants. Omari $e t a l^{11}$ included preterm infants between 34 and 40 weeks gestational age, Corvaglia et $a l^{12}$ and Corvaglia $e a^{13}$ included $\leq 33$ weeks gestational age and Wheatley and Kennedy ${ }^{10}$ included those with a gestational age of $<37$ weeks at birth and a corrected gestational age at enrolment of $<44$ weeks. Orenstein et $a l^{14}$ and Davidson $e t a l^{15}$ included both preterm infants and full-term infants. The inclusion criteria for each study defined GORD differently (table 1).

Primary outcome: all six studies assessed various reflux symptoms. Four trials reported GOR episodes based on 24-hour $\mathrm{pH} /$ impedance monitoring. ${ }^{11-13} 15$ Three trials reported bradycardia (Davidson et al, ${ }^{15}$ Omari et $a l,{ }^{11}$ Wheatley and Kennedy ${ }^{10}$ ) and three trials reported apnoea (Corvaglia et $a l^{13}{ }^{13}$ Davidson $e t a l,{ }^{15}$ Omari et $a l^{11}$ ). The other reported outcomes included vomiting, apnoea, bradycardia, oxygen desaturation, gagging, back arching and irritability/crying/fussing. ${ }^{10} 11{ }^{15}$ None of the studies reported on the prespecified secondary outcomes, namely: time taken to establish full enteral feeds, length of hospital stay, NEC and suspected or proven sepsis. Orenstein et al looked at treatment-emergent adverse events (AEs) and serious adverse events (SAEs) including upper respiratory tract infections, constipation, dermatitis, ear infections, fever, lower respiratory tract infection, respiratory tract congestion, rhinorrhoea, candidiasis, diarrhoea (excluding infective), vomiting, alkaline phosphatase increase and others.

\section{Effects of interventions}

Sodium alginate (Gaviscon) versus placebo

Thirty-two patients with a median gestational age of 30 weeks were enrolled in Corvaglia et al. ${ }^{12}$ Participants were fed eight times over a 24 hours period, with meals alternatively given with drug ('drug-given' (DG)) and without drug ('drug-free' (DF)). Twenty-eight patients with a median gestational age of 30 weeks were enrolled in Corvaglia et $_{\text {al. }}{ }^{13}$ Participants were studied between the hours of 09:00 and 18:00, when they were recorded twice, for 3 hours each time, after one DG meal and one DF meal, the order of which was randomly chosen.

There was significant decrease in total GOR episodes detected only by $\mathrm{pH}$ monitoring, acid GOR episodes detected by multichannel intraluminal impedance monitoring, reflux index detected only by $\mathrm{pH}$ monitoring and proximal GORs. ${ }^{12} 13$

All other outcomes were not significant (liquid GORs, mixed GORs, non-acid GOR episodes detected by multichannel intraluminal impedance monitoring, non-acid MII-GOR-bolus exposure index and distal GORs). ${ }^{12}$ No differences in the number of total apnoea episodes, central apnoeas, obstructive apnoeas, mixed apnoeas, desaturations, bradycardia, pathological apnoeas were found between DG and DF periods ( $p$ value was not significant $)^{13}$ (table 2).

\section{Esomeprazole versus placebo}

Fifty-two patients with a mean gestational age of 31 were enrolled in the study by Davidson et al. One did not have valid efficacy data and was excluded from the reported results. Participants were randomly selected to receive either esomeprazole $(n=25)$ or placebo $(n=26)$, once daily, for up to 14 days. $^{15}$

No significant results were obtained from this study, which was discontinued prematurely due to poor enrolment ${ }^{15}$ (table 3).

\section{Omeprazole versus placebo}

Ten preterm infants with a mean postmenstrual age of $36.1 \pm 0.7$ weeks and mean postnatal age of $50 \pm 9$ days were enrolled in the study by Omari et al. ${ }^{11}$ Participants were given omeprazole for 7 days and placebo for 7 days in randomised order. At the end of each week of interventions, a 24-hour oesophageal and gastric $\mathrm{pH}$ monitoring study was performed. Analyses on the basis of $\mathrm{pH}$ recordings showed that omeprazole therapy significantly reduced the oesophageal acid exposure $\%$ time $\mathrm{pH}<4$ and reduced gastric acidity $\%$ time $\mathrm{pH}<4^{11}$ (table 3 ). There 
Table 2 Effect of alginates (Gaviscon) use in preterm infants

\begin{tabular}{|c|c|c|c|}
\hline Studies & Antacids & Control & P values* \\
\hline \multicolumn{4}{|l|}{ Corvaglia et $a l^{12}$} \\
\hline Total GORs & $49.00(28.50-67.00)$ & $58.50(33.50-75.75)$ & 0.024 \\
\hline Liquid GORs & $21.50(12.25-32.00)$ & $21.50(13.50-39.75)$ & 0.432 \\
\hline Gaseous GORs & $2.00(0.25-7.50)$ & $3.00(0.00-14.75)$ & 0.040 \\
\hline Mixed GORs & $3.00(2.00-5.75)$ & $3.00(1.00-5.00)$ & 0.614 \\
\hline $\mathrm{pH}-\mathrm{GORs}$ & $17.00(6.00-29.75$ & $29.00(13.50-44.50)$ & 0.002 \\
\hline aMII-GORs & $4.00(2.00-8.25)$ & $6.00(2.25-11.75)$ & 0.050 \\
\hline NaMII-GORs & $19.00(10.00-32.75)$ & $18.50(8.50-33.75)$ & 0.743 \\
\hline $\mathrm{RlpH}$ & $4.0(1.8-13.1)$ & $7.6(3.3-17.0)$ & 0.030 \\
\hline aMII-GOR-BEI & $0.2(0.1-0.6)$ & $0.4(0.1-1.0)$ & 0.036 \\
\hline NaMII-GOR-BEI & $1.2(0.5-1.9)$ & $0.9(0.5-1.7)$ & 0.822 \\
\hline Distal GORs (no.) & $18.00(11.25-27.00$ & $15.00(9.25-26.00)$ & 0.959 \\
\hline Proximal GORs (no.) & $5.50(4.00-9.00)$ & $7.50(3.00-12.00)$ & 0.030 \\
\hline \multicolumn{4}{|l|}{ Corvaglia et $a l^{13}$} \\
\hline Total GOR episodes & $9(0-33)$ & $20.5(1-42)$ & 0.001 \\
\hline $\mathrm{pH}-\mathrm{GOR}$ & $2(0-26)$ & $7.5(0-23)$ & 0.004 \\
\hline aMII-GOR & $1(0-5)$ & $3(0-16)$ & 0.001 \\
\hline NaMII-GOR & $4.5(0-22)$ & $6(1-21)$ & 0.145 \\
\hline $\mathrm{RIpH}$ & $0.9(0-23.2)$ & $8.4(0-44.2)$ & 0.001 \\
\hline aMII-BEI & $0.17(0-2)$ & $0.5(0-8.1)$ & 0.002 \\
\hline NaMII-BEI & $0.75(0-5.7)$ & $1.0(0.1-9.2)$ & 0.982 \\
\hline Total apnoea episodes & $9.5(0-35)$ & $9.5(0-44)$ & 0.99 \\
\hline Central apnoeas & $3.5(0-25)$ & $5(0-34)$ & 0.22 \\
\hline Obstructive apnoeas & $1(0-8)$ & $1(0-10)$ & 0.10 \\
\hline Mixed apnoeas & $3(0-16)$ & $4(0-17)$ & 0.98 \\
\hline Desaturations & $0.5(0-10)$ & $0(0-12)$ & 0.41 \\
\hline Bradycardia & $0(0-3)$ & $0(0-3)$ & 0.32 \\
\hline Pathological apnoeas & $0(0-5)$ & $0(0-7)$ & 0.69 \\
\hline
\end{tabular}

Values are reported as median (IQR).

${ }^{*} \mathrm{P}$ values as provided in the original publication. The level of significance was set at $\mathrm{p} \leq 0.05$.

aMII-GOR, acid GOR episode detected by MII; aMII-GOR-BEI, acid MII-GOR-bolus exposure index; GOR, gastro-oesophageal reflux; MII, multichannel intraluminal impedance monitoring; NaMII-GOR, non-acid GOR episode detected by MII; NaMII-GOR-BEI, non-acid MII-GORbolus exposure index; $\mathrm{pH}-\mathrm{GOR}$, GOR episodes detected only by $\mathrm{pH}$ monitoring; RIpH, reflux index detected only by $\mathrm{pH}$ monitoring.

were no significant changes to symptom frequency (vomiting, apnoea, bradycardia, choking, behavioural changes) or blood results.

\section{Lansoprazole versus placebo}

One hundred sixty-two patients were enrolled in the study by Orenstein et al, 44 of whom were premature infants, with a median gestational age at birth of 35 (IQR 25-39) weeks. ${ }^{13}$ Participants were randomly selected to take either lansoprazole $(n=81)$ or a placebo $(n=81)$ for up to 4 weeks. There was a $35 \%$ loss of follow-up for participants receiving lansoprazole and $36 \%$ for participants receiving placebo. Lansoprazole and placebo produced identical responder numbers (54\%). Responder status was defined as a $\geq 50 \%$ reduction from baseline in either percentage of feedings with crying episode(s) or duration (in minutes) of episodes averaged across feedings. No significant results were obtained from this trial. SAEs, particularly lower respiratory tract infections, occurred more frequently with lansoprazole than with placebo group (10 vs $2 ; \mathrm{p}=0.032$ ) (table 3 ).

\section{Metoclopramide and ranitidine versus placebo}

Eighteen patients were enrolled, and 17 completed the study, with a gestational age of $29 \pm 3$ weeks. There was a significant decrease in the number of bradycardia episodes per day in the mean combined placebo time periods compared with the mean combined drug time periods (3.6 (SD 2.7) vs 4.6 (SD 3.1)), p=0.04), and in bradycardia episodes over time $(\mathrm{p}<0.001)$, with fewer episodes during placebo periods. ${ }^{10}$ 
Table 3 Effect of proton pump inhibitors use in preterm infants

\begin{tabular}{|c|c|c|c|}
\hline Studies & Antacids & Control & \\
\hline Esomeprazole vs placebo & 25 infants & 26 infants & P values* \\
\hline \multicolumn{4}{|l|}{ Davidson et $a^{15}$} \\
\hline $\begin{array}{l}\text { Total number of GORD-related signs and symptoms, percentage of } \\
\text { change from baseline after } 14 \text { days of treatment }\end{array}$ & $-14.7 \%$ & $14.1 \%$ & 0.92 \\
\hline Gastrointestinal events, percentage of change from baseline & $-8.39 \%$ & $10.16 \%$ & 0.42 \\
\hline Neurobehavioural events, percentage of change from baseline & $-3.54 \%$ & $-3.98 \%$ & 0.94 \\
\hline Cardiorespiratory events, percentage of change from baseline & $-38.94 \%$ & $-41.17 \%$ & 0.89 \\
\hline Omeprazole vs placebo & 10 infants & 10 infants & \\
\hline \multicolumn{4}{|l|}{ Omari et al ${ }^{11}$} \\
\hline Gastric acidity (\%time $\mathrm{pH}<4)$, mean \pm SEM & $13.9 \pm 5.1$ & $53.8 \pm 6.8$ & $<0.0005$ \\
\hline Oesophageal acid exposure (\%time $\mathrm{pH}<4$ ), mean \pm SEM & $4.9 \pm 3.4$ & $19.0 \pm 4.5$ & $<0.01$ \\
\hline No. of acid GOR episodes, mean \pm SEM & $119.4 \pm 20$ & $59.6 \pm 26.7$ & $<0.05$ \\
\hline No. of oesophageal acid GOR $>5$ min, mean \pm SEM & $8.0 \pm 2.1$ & $3.0 \pm 2.0$ & $<0.01$ \\
\hline Lansoprazole vs placebo & 81 infants & 81 infants & \\
\hline \multicolumn{4}{|l|}{ Orenstein et $\mathrm{al}^{14}$} \\
\hline Primary efficacy: responder rate, n (\%) & $44(54 \%)$ & $44(54 \%)$ & NS \\
\hline AEs, n (\%) & $50(62 \%)$ & $37(46 \%)$ & NS \\
\hline SAEs, n (\%) & $10(12 \%)$ & $2(2 \%)$ & 0.032 \\
\hline
\end{tabular}

${ }^{*} \mathrm{P}$ values as provided in the original publication.

AEs, adverse events; GOR, gastro-oesophageal reflux; GORD, gastro-oesophageal reflux disease; NS, not significant; SAEs, serious adverse events.

\section{DISCUSSION}

This systematic review reveals that there is insufficient evidence to support the efficacy and safety of antacid therapies in preterm infants. Four out of the six studies included in the review were crossover trials, where the patient receives both interventions at different time intervals. The carry-over effect, where the intervention taken in the first period is still effective when the second intervention is being taken, is a major limitation in crossover designs. These effects cannot be estimated separately. To minimise the risk of a carry-over effect, it can be effective to allow a 'washout' period between interventions. Wheatley and Kennedy allowed a 24-hour washout period at the beginning of the second and third time periods. ${ }^{10}$ Omari et $a l,{ }^{11}$ Corvaglia et $a l^{12}$ and Corvaglia et $a l^{13}$ did not appear to have a washout period. When deciding whether to use a crossover design, it is important to consider whether the outcome that is being treated will change naturally over time. This does not seem like it would be an issue in the studies by Corvaglia et $a l^{12}$ and Corvaglia et $a l,{ }^{13}$ due to the overall treatment and observation period being short at just 24 hours. It may be problematic, however, for the study by Omari et $a l,{ }^{11}$ with each infant receiving a week of each intervention. Wheatley and Kennedy studied infants over a 2-week period and splits one intervention so it is given at the start and end of the 2-week period. This study shows a significant decrease in bradycardias over time, which may be evidential of a natural improvement of the outcome overtime, due to the infants' growth. ${ }^{10}$

\section{Alginates}

Sodium alginate significantly reduced acid GOR episodes, although had no effect on the reduction of apnoeas. Corvaglia et $a l^{12}$ reports that participants were observed over a 24-hour period, and data were collected after eight meals. There may have been selective reporting in the study by Corvaglia et $a l,{ }^{13}$ with authors only reporting data from a 6-hour period of observation instead of the full 24 hours data, thus presenting more significant results. This discrepancy diminishes the validity of the reports and applicability to clinical practice.

\section{Proton pump inhibitors}

Omari et al showed that $0.7 \mathrm{mg} / \mathrm{kg}$ omeprazole given once daily was effective in reducing the frequency of acid reflux episodes and the overall degree of oesophageal acid exposure in premature infants. ${ }^{11}$ Despite the normalisation of acid reflux in most patients, the number of symptomatic events was not significantly changed. The drug-dosing regimen used appeared safe based on AE reporting and blood screening. However, due to the small number of participants enrolled in the study $(n=10)$, it would be difficult to state whether this evidence is applicable in everyday practice and more trials must be carried out into the efficacy of omeprazole. There were no significant differences in the number of GORD-related signs 
and symptoms between neonates receiving esomeprazole or lansoprazole versus placebo. ${ }^{14}{ }^{15}$ SAEs occurred more frequently with lansoprazole than with placebo group. It is unclear whether loss to follow-up caused a significant imbalance in characteristics between lansoprazole and placebo group. Therefore, applicability into everyday practice is low because loss to follow-up can severely compromise validity as those lost to follow-up could have a different prognosis than those who complete the study. The number of AEs was similar between neonates receiving esomeprazole versus placebo. Both Orenstein $e t$ $a l$ and Davidson et al had notable conflicts of interest that were reported in the study, as shown in the online supplementary appendix 3 . The trials of both studies were sponsored by drug companies, which may have affected the design and outcomes of the trial as well as the reporting of results. However, no significant results were found in either trial, and so no results were reported in favour of the drug under trial. ${ }^{1415}$

\section{Histamine-2 -receptor antagonists}

A retrospective cohort study conducted by Romaine $e t$ $a l^{16}$ in the USA concluded that H2 blocker use was associated with increased risk of the combined outcome of death, NEC or sepsis in hospitalised very low birthweight infants (VLBW). Another recent retrospective cohort study showed that ranitidine use was associated with an increased risk of infections and mortality in preterm infants, but not with NEC. ${ }^{17}$ Wheatley and Kennedy showed that ranitidine did not reduce, and may have increased, bradycardia episodes in preterm infants with bradycardia attributed to GOR. ${ }^{10}$ Wheatley and Kennedy compared the combination of two interventions together against a placebo, ranitidine, a H2 RA and metoclopramide, a dopamine receptor antagonist. With regard to applicability, the data derived from this study actually suggest that combining ranitidine and metoclopramide may be detrimental to patients and should therefore be avoided in clinical practice, as it showed a significant increase in bradycardia episodes during drug periods. This may be caused by significant interactions between the two drugs that could either decrease the efficacy of either or both of drugs or perhaps cause AEs. Leucuta $e t$ al found pharmacokinetic changes, such as an increased half-life, in metoclopramide, when taken with ranitidine.$^{18}$ It is also quite likely that this is a chance finding, given the small number of participants enrolled in the study $(n=18)$. Previous studies into the combined efficacy of ranitidine and metoclopramide suggest that this treatment is effective at increasing gastric $\mathrm{pH}$ and reducing the side effects of GORD, and do not mention any significant drug induced side effects or drug interactions. ${ }^{19} 20$

\section{LIMITATIONS}

A number of limitations are worth noting, not all studies met the inclusion criteria outlined in the methods. We initially stated that only preterm infants $<37$ weeks gestation were to be included in this review; however, both Davidson et al and Orenstein et al included data for full-term infants as well as preterm, some of whom were $>37$ weeks gestation. The authors were contacted to obtain exclusively preterm data, however, replies were not received. We included these studies in this review due to the high percentage of preterm infants enrolled in the trials. The methods stated that the only interventions that were to be considered were H2 RAs, PPIs and alginates; however, Wheatley and Kennedy assessed the combined effects of both metoclopramide (dopamine receptor antagonist) and ranitidine (H2 RA). ${ }^{10}$ We still decided to report this outcome as the inclusion of the H2 RA as it is of interest to the reader in general who must bear in mind this was a combined intervention. Studies included in the review were heterogeneous in terms of design, study characteristics such as age of participants and interventions considered for the treatment of GORD. Studies also had small sample sizes. This limits the conclusions that can be drawn from this review; however, it highlights the gaps in the evidence.

\section{Agreements or disagreements with other studies or reviews}

To our knowledge, this review is the first to look into the effects of antacids in preterm infants.

Terrin et al in a retrospective study of 274 VLBW infants reported that the risk of NEC, nosocomial infection and mortality were significantly higher in the infants exposed to ranitidine. ${ }^{4}$ However, non-prospective, non-controlled and unblinded design features limited its significance. A Cochrane review by Tighe et al looking at the effects of pharmacological treatment for the management of GORD in children concluded that although there is evidence to support pharmacological use in older children, use in infants is unsupported due to lack of robust RCT evidence. ${ }^{21}$

Cohen $e t$ al in a recent review suggested that the use of GORD medications should only be used after non-pharmacological measures have been taken with incomplete success as acid suppression may place immune-deficient infants and children at risk for the development of lower respiratory tract infections and nosocomial sepsis. ${ }^{22}$

\section{AUTHORS' CONCLUSIONS}

There is insufficient evidence on the efficacy and safety of antacids in preterm infants.

The lack of research in this area of medicine is a problem that must be addressed in this population of patients. Adequately powered, RCTs in preterm infants are needed to determine the safety and efficacy of these commonly used medications.

Contributors ED had full access to all study data and takes responsibility for the integrity and accuracy of the data. Study concept and design: JD and BD conceived and designed the study. Acquisition of data: $\mathrm{CM}$ and ED. Analysis and interpretation of data: $E D, C M, P K, B D$ and JD. Drafting of the manuscript: ED, PK and JD. Critical revision of the manuscript for important intellectual content: JD. All authors 
approved the final manuscript as submitted and agree to be accountable for all aspects of the work.

Funding This research received no specific grant from any funding agency in thepublic, commercial or not-for-profit sectors.

Competing interests None declared.

Patient consent Not required.

Provenance and peer review Not commissioned; externally peer reviewed.

Open access This is an open access article distributed in accordance with the Creative Commons Attribution Non Commercial (CC BY-NC 4.0) license, which permits others to distribute, remix, adapt, build upon this work non-commercially, and license their derivative works on different terms, provided the original work is properly cited, appropriate credit is given, any changes made indicated, and the use is non-commercial. See:@http://creativecommons.org/licenses/by-nc/4.0/.

\section{REFERENCES}

1. Corvaglia L, Monari C, Martini S, et al. Pharmacological therapy of gastroesophageal reflux in preterm infants. Gastroenterol Res Pract 2013;2013:1-12.

2 Rossor T, Andradi G, Bhat R, et al. Investigation and management of gastro-oesophageal reflux in United Kingdom neonatal intensive care units. Acta Paediatr 2018;107:48-51.

3. Guillet R, Stoll BJ, Cotten CM, et al. Association of H2-blocker therapy and higher incidence of necrotizing enterocolitis in very low birth weight infants. Pediatrics 2006;117:e137-e142.

4. Terrin G, Passariello A, De Curtis M, et al. Ranitidine is associated with infections, necrotizing enterocolitis, and fatal outcome in newborns. Pediatrics 2012;129:e40-e45.

5. Liberati A, Altman DG, Tetzlaff J, et al. The PRISMA statement for reporting systematic reviews and meta-analyses of studies that evaluate health care interventions: explanation and elaboration. $J$ Clin Epidemiol 2009;62:e1-e34.

6. Higgins J, Green S. Cochrane Handbook for Systematic Reviews of Interventions, version 5.1.0 (updated March 2011). The Cochrane Collaboration. 2011. www.cochrane-handbook.org

7. Higgins JP, Altman DG, Gøtzsche PC, et al. The Cochrane Collaboration's tool for assessing risk of bias in randomised trials. BMJ 2011;343:d5928.

8. Guyatt G, Oxman AD, Akl EA, et al. GRADE guidelines: 1. Introduction-GRADE evidence profiles and summary of findings tables. J Clin Epidemiol 2011;64:383-94.
9. Orenstein SR, Cohn JF, Shalaby TM, et al. Reliability and validity of an infant gastroesophageal reflux questionnaire. Clin Pediatr 1993;32:472-84.

10. Wheatley E, Kennedy KA. Cross-over trial of treatment for bradycardia attributed to gastroesophageal reflux in preterm infants. J Pediatr 2009;155:516-21.

11. Omari TI, Haslam RR, Lundborg P, et al. Effect of omeprazole on acid gastroesophageal reflux and gastric acidity in preterm infants with pathological acid reflux. J Pediatr Gastroenterol Nutr 2007;44:41-4.

12. Corvaglia L, Aceti A, Mariani E, et al. The efficacy of sodium alginate (Gaviscon) for the treatment of gastro-oesophageal reflux in preterm infants. Aliment Pharmacol Ther 2011a;33:466-70.

13. Corvaglia L, Spizzichino M, Zama D, et al. Sodium Alginate

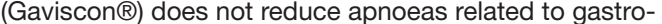
oesophageal reflux in preterm infants. Early Hum Dev 2011b;87:775-8.

14. Orenstein SR, Hassall E, Furmaga-Jablonska W, et al. Multicenter, double-blind, randomized, placebo-controlled trial assessing the efficacy and safety of proton pump inhibitor lansoprazole in infants with symptoms of gastroesophageal reflux disease. J Pediatr 2009;154:514-20.

15. Davidson G, Wenzl TG, Thomson M, et al. Efficacy and safety of once-daily esomeprazole for the treatment of gastroesophagea reflux disease in neonatal patients. J Pediatr 2013;163:692-8.

16. Romaine A, Ye D, Ao Z, et al. Safety of histamine-2 receptor blockers in hospitalized VLBW infants. Early Hum Dev 2016;99:27-30.

17. Santana RNS, Santos VS, Ribeiro-Júnior RF, et al. Use of ranitidine is associated with infections in newborns hospitalized in a neonata intensive care unit: a cohort study. BMC Infect Dis 2017;17:375

18. Leucuta A, Vlase L, Farcău $D$, et al. Pharmacokinetic interaction study between ranitidine and metoclopramide. Rom J Gastroenterol 2004;13:211-4

19. Hong JY. Effects of metoclopramide and ranitidine on preoperative gastric contents in day-case surgery. Yonsei Med J 2006;47:315-8.

20. Bala I, Prasad K, Bhukal I, et al. Effect of preoperative oral erythromycin, erythromycin-ranitidine, and ranitidinemetoclopramide on gastric fluid $\mathrm{pH}$ and volume. $J$ Clin Anesth 2008;20:30-4.

21. Tighe M, Afzal NA, Bevan A, et al. Pharmacological treatment of children with gastrooesophageal reflux (Review). Cochrane Database Syst Rev 2014;11:CD008550.

22. Cohen S, Bueno de Mesquita M, Mimouni FB, et al. Adverse effects reported in the use of gastroesophageal reflux disease treatments in children: a 10 years literature review. $\mathrm{Br} J$ Clin Pharmacol 2015;80:200-8 